\title{
$4707^{\mathrm{a}}$ sesión
}

Viernes 14 de febrero de 2003, a las 10.00 horas

Nueva York

Presidente: Sr. Fischer.

(Alemania)

Miembros: Angola

Bulgaria

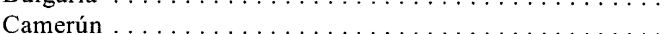

Chile

Sr. Gaspar Martins

China ........................

Sr. Tafrov

Sr. Belinga-Eboutou

Sra. Alvear Valenzuela

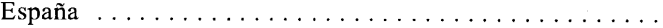

Sr. Tang Jiaxuan

Estados Unidos de América $\ldots \ldots \ldots \ldots \ldots \ldots \ldots \ldots \ldots$

Federación de Rusia

Sra. Palacio Vallelersundi

Francia

Sr. Powel

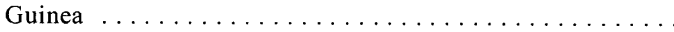

Sr. Ivanov

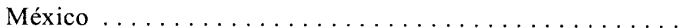

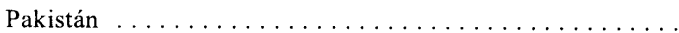

Reino Unido de Gran Bretaña e Irlanda del Norte . . . . . . .

República Árabe Siria Sr. Galouzeau de Villepin

Sr. Traoré

Sr. Derbez

Sr. Akram

Sr. Straw

Sr. Al-Shara'

\section{Orden del día}

La situación entre el Iraq y Kuwait

La presente acta contiene la versión literal de los discursos pronunciados en español y de la interpretación de los demás discursos. El texto definitivo será reproducido en los Documentos Oficiales del Consejo de Seguridad. Las correcciones deben referirse solamente a los discursos originales y se enviarán firmadas por un miembro de la delegación interesada e incorporadas en un ejemplar del acta, al Jefe del Servicio de Actas Literales, oficina C-178. 
central que desempeñan. Todos deberíamos valorar estos esfuerzos.

Hemos estudiado la propuesta francesa para reforzar la labor de los inspectores. Con las inspecciones se han conseguido resultados considerables que no se hubieran logrado mediante la fuerza militar. Así pues, respaldamos las ideas de Francia porque son una alternativa a la guerra. Constituyen una base para reforzar el régimen de inspecciones a fin de que pueda ejecutar cuanto antes la tarea que se le ha confiado. El cumplimiento de esta tarea inmediatamente se plasmará, a través de medidas adecuadas, en el levantamiento de las sanciones impuestas al Iraq de conformidad con la resolución 687 (1990) del Consejo de Seguridad. También se traducirá en la activación del párrafo 14 de esa resolución, según el cual se designaría al Oriente $\mathrm{Me}$ dio como zona libre de todo tipo de armas de destrucción en masa: nucleares, bacteriológicas y químicas, sin exceptuar a ningún Estado, incluido Israel, que es el único que ha adquirido todas esas armas mortíferas.

En conclusión, éste es un verdadero momento histórico. La guerra en el siglo XXI no es un juego. Ha pasado a ser una tragedia que la historia condena. Trabajemos en aras de la paz, porque podemos lograrla si la buscamos de buena fe, con determinación firme y voluntad política. Estas exigencias están fácilmente disponibles para quienes son fieles a la Carta de las $\mathrm{Na}$ ciones Unidas, una carta que, después de todo lo que se ha dicho y se ha hecho, sigue siendo la única autoridad capaz de mantener la paz y la seguridad del mundo.

El Presidente (habla en inglés): Tiene ahora la palabra el Ministro de Relaciones Exteriores de Francia, Excmo. Sr. Dominique Galouzeau de Villepin.

Sr. Galouzeau de Villepin (Francia) (habla en francés): Doy las gracias al Sr. Blix y al Sr. ElBaradei por las indicaciones que nos acaban de proporcionar en lo que respecta a la continuación de las inspecciones en el Iraq. Una vez más, quisiera manifestarles la confianza y el apoyo pleno de Francia a su misión.

Saben ustedes el valor que Francia, desde el comienzo de la crisis en el Iraq, atribuye a la unidad del Consejo de Seguridad. Esta unidad se basa hoy en dos elementos esenciales. Perseguimos juntos el objetivo de un desarme efectivo del Iraq. En este ámbito, tenemos la obligación de obtener resultados. No dudemos de nuestro compromiso común en este sentido. Asumimos en forma colectiva esta gran responsabilidad, que no debe plegarse a los motivos ocultos ni a los juicios basados sólo en las intenciones. Seamos claros: ninguno de nosotros se siente complacido en lo más mínimo en relación con Saddam Hussein ni con el régimen del Iraq.

Al aprobar por unanimidad la resolución 1441 (2002), hemos señalado colectivamente que estamos de acuerdo con la acción en dos etapas que propuso Francia: la decisión del desarme mediante las inspecciones, $y$, en caso de que fracase esta estrategia, el examen por el Consejo de Seguridad de todas las opciones, incluido el recurso a la fuerza. En el caso de que las inspecciones fracasaran, y únicamente en ese caso, se podría justificar una segunda resolución.

La cuestión que se plantea ahora es sencilla: ¿consideramos con toda convicción que el desarme mediante las misiones de inspección es ahora un camino sin salida? O ¿estimamos que aún no se han explorado todas las posibilidades en materia de inspección que ofrece la resolución 1441 (2002)?

En repuesta a ese interrogante, Francia está convencida de dos cosas. Primero, la opción de las inspecciones aún no se ha agotado y puede aportar una respuesta eficaz al imperativo del desarme del Iraq. Segundo, el empleo de la fuerza tendría consecuencias tan graves para los seres humanos, para la región y para la estabilidad internacional que no debería preverse sino como último recurso.

Ahora bien, ¿qué acabamos de escuchar en los informes de los Sres. Blix y ElBaradei? Acabamos de escuchar que las inspecciones están dando resultados. Naturalmente, cada uno de nosotros quiere que se logre más. Y juntos seguiremos ejerciendo presión sobre Bagdad para conseguir más. Sin embargo, las inspecciones están dando resultados.

En su intervención anterior ante el Consejo de Seguridad el 27 de enero, el Presidente Ejecutivo de la Comisión de las Naciones Unidas de Vigilancia, Verificación e Inspección (UNMOVIC) y el Director General del Organismo Internacional de Energía Atómica (OIEA) habían identificado con precisión los ámbitos en los cuales se esperaban adelantos. En lo que respecta a varios de estos ámbitos, se han obtenido progresos significativos. En las esferas química y biológica, los iraquíes han entregado nuevos documentos a los inspectores. También anunciaron la creación de comisiones de investigación, dirigidas por los antiguos responsables de los programas de armamentos, de conformidad con lo solicitado por el Sr. Blix. En el ámbito 
balístico, las informaciones que proporcionó el Iraq han permitido que los inspectores también lograran avances. Conocemos con precisión la capacidad real del misil Al-Samoud. Ahora, es preciso proceder a desmantelar los programas no autorizados, de conformidad con las conclusiones del Sr. Blix. En el ámbito nuclear, se han transmitido informaciones útiles al Organismo Internacional de Energía Atómica sobre los puntos importantes que mencionó el Sr. ElBaradei el 27 de enero último: la adquisición de imanes que puedan servir para la obtención de uranio enriquecido, y la lista de los contactos entre el Iraq y los países que pueden haberle proporcionado uranio.

Ésta es precisamente la esencia de la lógica de la resolución 1441 (2002), que debe garantizar la eficacia de las inspecciones mediante una identificación precisa de los programas prohibidos y su posterior eliminación. Todos somos conscientes de que el éxito de las inspecciones supone que alcancemos una cooperación plena y total del Iraq. Francia no ha dejado de exigirlo.

Empiezan a surgir verdaderos progresos. El Iraq ha aceptado que aparatos de reconocimiento aéreo sobrevuelen su territorio. Ha permitido que los científicos iraquíes sean interrogados sin testigos por los inspectores. Un proyecto de ley que prohíbe todas las actividades relacionadas con los programas de armas de destrucción en masa se encuentra en curso de aprobación, de conformidad con un pedido que habían realizado hace tiempo los inspectores. El Iraq debe proporcionar una lista detallada de los expertos que, en 1991, presenciaron la destrucción de los programas militares.

Naturalmente, Francia espera que esos compromisos se verifiquen durante largo tiempo. Por otra parte, debemos mantener una presión firme sobre el Iraq para que vaya más allá en materia de colaboración.

Estos adelantos nos brindan la convicción de que la vía de las inspecciones puede ser eficaz. Pero no debemos ocultar la magnitud de la labor que aún tiene que realizarse: todavía se deben aclarar varias cuestiones, deben llevarse a cabo verificaciones y, sin duda, aún tienen que destruirse instalaciones y materiales.

Para ello, debemos ofrecer a las inspecciones todas las oportunidades de éxito. El 5 de febrero formulé propuestas ante el Consejo. Posteriormente, las especificamos en un documento de trabajo dirigido a los Sres. Blix y ElBaradei y se las comunicamos a los miembros del Consejo. ¿Cuál es su contenido? Se trata de propuestas prácticas y concretas, que pueden ponerse en práctica rápidamente y que están destinadas a fortalecer la eficacia de las operaciones de inspección. Se inscriben en el marco de la resolución 1441 (2002) y, por consiguiente, no requieren ninguna nueva resolución del Consejo. Deben respaldar los esfuerzos realizados por los Sres. Blix y ElBaradei. Naturalmente, ellos son los que están mejor calificados para decirnos cuáles de ellas desean elegir para garantizar la mayor eficacia de su labor.

En sus informes, los Sres. Blix y ElBaradei han formulado observaciones útiles y prácticas. Francia ya ha anunciado que pone medios adicionales a disposición de los Sres. Blix y ElBaradei, comenzando con los aviones de reconocimiento aéreo, Mirage IV.

Sí, oigo críticas: hay quienes piensan que, por principio, las inspecciones no pueden ser eficaces en modo alguno. Sin embargo, quiero recordar que ese es el fundamento mismo de la resolución 1441 (2002), y que las inspecciones sí dan resultados. Puede que se considere que no son suficientes, pero ahí están. Hay quienes opinan que la continuación del proceso de inspección sería una especie de maniobra dilatoria para impedir una intervención militar. Ello, naturalmente, plantea la cuestión del tiempo que se ha dado al Iraq. Estamos aquí, en el centro del debate. Lo que está en juego es nuestra credibilidad y nuestro sentido de la responsabilidad.

Tengamos el valor de decir las cosas como son. Hay dos opciones. A priori, la opción de la guerra pudiera parecer la más rápida, pero no olvidemos que, después de haber ganado la guerra, será necesario construir la paz. No nos llamemos a engaño: eso será largo y difícil, porque será necesario preservar la unidad del Iraq y restablecer, de forma duradera, la estabilidad de un país y de una región gravemente afectados por la intrusión de la fuerza. Ante esa perspectiva, existe la alternativa que ofrecen las inspecciones y que permiten avanzar, día a día, por el camino del desarme eficaz y pacífico del Iraq. Al final, ¿acaso no es éste el camino más seguro y rápido?

Nadie puede afirmar hoy que el camino de la guerra será más breve que el de las inspecciones. Nadie puede afirmar tampoco que ese camino pueda conducir a un mundo más seguro, más justo y más estable, porque la guerra es siempre la sanción de un fracaso. ¿Sería ese nuestro único recurso ante los numerosos desafíos de hoy? 
En consecuencia, demos a los inspectores de las Naciones Unidas el tiempo necesario para que cumplan su misión, pero mantengámonos vigilantes y pidamos a los Sres. Blix y ElBaradei que presenten informes periódicos al Consejo. Por su parte, Francia propone que celebremos una nueva sesión, a nivel ministerial, el 14 de marzo, a fin de evaluar la situación. Entonces podremos evaluar los progresos hechos y lo que quede por hacer.

En este contexto, el uso de la fuerza no se justifica en este momento. Existe una alternativa a la guerra: desarmar al Iraq por medio de las inspecciones. Además, un recurso prematuro a la opción militar tendría numerosas consecuencias. Ahora, la autoridad de nuestra acción se basa en la unidad de la comunidad internacional. Una intervención militar prematura pondría en tela de juicio esa unión, lo que le restaría legitimidad y, a la larga, eficacia. Esa intervención podría tener consecuencias incalculables para la estabilidad de una región lacerada y frágil. Reforzaría el sentimiento de injusticia, agravaría las tensiones y podría allanar el camino que conduce hacia otros conflictos.

Todos compartimos la misma prioridad: luchar inexorablemente contra el terrorismo. Esa lucha exige una determinación total. Después de la tragedia del 11 de septiembre, ésta es una de nuestras principales responsabilidades ante nuestros pueblos. Francia, país que se ha visto duramente afectado en varias ocasiones por este terrible flagelo, se ha movilizado por completo para acometer esta lucha que nos interesa a todos y que todos debemos llevar adelante juntos. Ese es el sentido de la sesión del Consejo de Seguridad que se celebró el 20 de enero, por iniciativa de Francia.

Hace diez días, el Secretario de Estado de los Estados Unidos expuso los presuntos vínculos que existen entre Al-Qaida y el régimen de Bagdad. Sobre la base de nuestras investigaciones llevadas a cabo hasta el momento y de las informaciones que hemos obtenido de nuestros aliados, nada nos permite afirmar que existan tales vínculos. Sin embargo, debemos evaluar el efecto que una acción militar impugnada podría tener a este respecto. ¿Acaso esa intervención no plantearía el riesgo de agravar las divisiones que existen entre las sociedades, las culturas y los pueblos, y que alimentan el terrorismo?

Francia siempre ha dicho que el mantenimiento de la paz no excluye la posibilidad de que un día sea necesario recurrir a la fuerza si en los informes de los inspectores se llega a la conclusión de que es imposible proseguir con las inspecciones. Si llegara ese momento, el Consejo debería pronunciarse y sus miembros tendrían que asumir plenamente su responsabilidad. Si así fuera, quiero recordar aquí las interrogantes que subrayé en nuestro debate del 4 de febrero, y que debemos responder. ¿En qué medida el carácter y el alcance de la amenaza justifican el recurso inmediato a la fuerza? ¿Cómo asegurar que los considerables riesgos que entraña una intervención de esa índole se puedan controlar realmente?

En cualquier caso, de llegar ese momento, la unión de la comunidad internacional sería la garantía de su eficacia. Además, suceda lo que suceda, las $\mathrm{Na}-$ ciones Unidas seguirian siendo el pilar fundamental de la paz que habría que construir. A los que se preguntan con angustia cuándo y cómo vamos a acceder a la guerra, quiero decirles que nada en este Consejo de Seguridad será resultado de la precipitación, de la incomprensión, del recelo ni del miedo. En este templo de las Naciones Unidas, somos los guardianes de un ideal, los guardianes de una conciencia. La enorme responsabilidad y el inmenso honor que tenemos nos deben llevar a dar prioridad al desarme por vías pacíficas.

Un viejo país, Francia, ubicado en un viejo continente como el mío, Europa, que ha conocido las guerras, la ocupación y la barbarie, quiere hacer llegar este mensaje al Consejo en el día de hoy. Este país, que no olvida y que sabe cuánto debe a los combatientes por la libertad de los Estados Unidos y de otras partes, siempre se ha erguido con firmeza ante la historia y ante la humanidad. Fiel a sus valores, Francia quiere actuar con decisión junto con todos los miembros de la comunidad internacional pues creemos en nuestra capacidad de construir, juntos, un mundo mejor.

El Presidente (habla en inglés): Tiene la palabra la Excma. Sra. Soledad Alvear Valenzuela, Ministra de Relaciones Exteriores de Chile.

Sra. Alvear Valenzuela (Chile): Deseo, en primer término, agradecer a los Sres. Blix y ElBaradei los detallados y cuidadosos informes que nos han entregado esta mañana sobre el desarrollo de las inspecciones de la Comisión de las Naciones Unidas de Vigilancia, Verificación e Inspección (UNMOVIC) y el Organismo Internacional de Energía Atómica (OIEA) en el Iraq. Ellos reflejan la integridad profesional que ha caracterizado el trabajo de las inspecciones, así como la honestidad con que se ha extraído y relatado la verdad, 
desde una situación no desprovista de complejidades y obstáculos. Hemos escuchado atentamente sus informes, animados por la disposición constructiva que es propia de un país que cree sinceramente en el valor del sistema multilateral, en la obligatoriedad de las resoluciones del Consejo de Seguridad y en la virtud que encierra la decisión de explorar todos los caminos posibles para el mantenimiento de la paz.

Mi Gobierno estudiará durante los próximos días estos informes con la detención necesaria para participar responsablemente en los debates en que el Consejo examinará la evolución de este proceso, buscando adoptar decisiones basadas en hechos, y no en meras hipótesis.

Sin embargo, lo que hemos escuchado esta mañana nos permite reconocer que perdura en el régimen que gobierna el Iraq una actitud ambivalente ante el proceso de inspección. Si bien existen indicaciones de progreso que podrían alentar la esperanza de un cambio decisivo de actitud de parte del régimen iraquí ante lo que le exige la comunidad internacional, se mantienen actitudes negativas y dilatorias que demuestran un ánimo de no cooperación y que alientan la sospecha acerca de la presencia de armas de destrucción masiva en su territorio.

A la luz de los antecedentes entregados por el Jefe de la UNMOVIC y el Director General del OIEA esta mañana, esperamos que el Gobierno del Iraq intensifique la cooperación, sin dilación, entregando la información requerida por los inspectores de manera de permitir la implementación efectiva de las resoluciones de este Consejo.

Ante este cuadro, deseo reiterar hoy día los puntos que han dado base a la posición de Chile desde el inicio de este debate.

En primer lugar, que las resoluciones del Consejo de Seguridad deben cumplirse, y cumplirse de forma completa, y que no cabe una aproximación selectiva hacia su disposición. Esto no es lo que hace el Iraq. Reconocemos, por lo tanto, que la mantención de la presión sobre el régimen de Saddam Hussein ha demostrado ser el único mecanismo capaz de inducir una cierta apertura y respeto ante las decisiones del Consejo. Ella debe, en consecuencia, mantenerse sin descanso ni atenuación. Reiteramos que, de acuerdo con lo señalado en los párrafos operativos 4 y 11 de la resolución 1441 (2002), el incumplimiento por parte del Iraq o toda injerencia del Iraq en el proceso de inspecciones notificado al Consejo por el Jefe de la UNMOVIC deberá ser examinado por el Consejo a fin de determinar si se cumplen plenamente todas sus resoluciones en la materia con objeto de asegurar la paz y seguridad internacionales. La resolución señala claramente que la infracción de sus obligaciones expone al Iraq a graves consecuencias.

Segundo, mi país considera que dentro del sentido terminante y urgente que anima la resolución 1441 (2002), el proceso de inspecciones debe mantenerse, fortalecerse y profundizarse, haciéndose de tal manera preciso e intrusivo que delate cualquier esfuerzo de engaño o evasión que intente el régimen iraquí. En este sentido esperamos con interés las opiniones que los inspectores entreguen acerca del valor y la aplicabilidad que pueden tener las propuestas formuladas por Francia. Sin embargo es evidente que los tiempos de los que disponemos no son infinitos. La gravedad de la situación demanda respuestas inmediatas y categóricas del régimen iraquí a los inspectores.

En tercer lugar, Chile considera imprescindible el rol que las Naciones Unidas y el Consejo de Seguridad deben jugar en esta crisis. Nos parece que sobre esta materia cabe realizar una reflexión particular. Hemos observado, quisiéramos decirlo con claridad y con desaliento, durante el último mes un grado creciente de división en el Consejo. Este hecho preocupante, que si bien tiene sus raíces en posturas legítimamente diferentes ante la crisis, se ha visto alentado por una voluntad insuficiente de escuchar y proponer. Deseamos contribuir a reencontrar el camino de un debate que recupere una práctica de trabajo que combine la convicción con el respeto de las preocupaciones ajenas. La capacidad de persuasión, con la tolerancia y, sobre todo, la paciencia. Tal como ha señalado recientemente el Secretario General en el examen de la actual situación:

"El Consejo debe proceder de una manera determinada, reflexiva y deliberada. Sus medidas deben ser vistas como firmes, efectivas, creibles y razonables, no sólo por los miembros del Consejo sino por el público en general."

Por eso concordamos con el Secretario General en que la unidad del Consejo es la base de cualquier acción internacional dotada de legitimidad y fuerza. Sólo un Consejo unido podrá adoptar con credibilidad las decisiones que correspondan para lograr el propósito de desarmar al régimen del Iraq. Por ello, nos sumamos decididamente a la invitación que nos hace el 
Secretario General de tomar el tiempo necesario para continuar explorando el consenso más amplio posible para encontrar una solución comprehensiva que devuelva al pueblo iraquí, que ha padecido tan prolongado sufrimiento, la plena participación en la comunidad internacional. Sólo animados por este espíritu podemos hacer verdadera la afirmación en la que todos hemos coincidido, la de agotar todos los medios de solución pacífica de este conflicto, reservando el uso de la fuerza para el momento en que ellos han sido probados por todos como imposibles.

El Presidente (habla en inglés): Tiene la palabra el Excmo. Sr. Tang Jiaxuan, Ministro de Relaciones Exteriores de China.

Sr. Tang Jiaxuan (China) (habla en chino): Permítaseme comenzar dando las gracias a los Sres. Blix y ElBaradei por informar al Consejo sobre la labor de inspección que llevan a cabo en el Iraq. El pasado noviembre, este Consejo adoptó la resolución 1441 (2002) por consenso, reiterando la firme determinación de la comunidad internacional de verificar y destruir las armas de destrucción en masa que posee el Iraq. En estos momentos, la cuestión del Iraq ha alcanzado su punto más crítico. La comunidad internacional comparte la esperanza universal de ver una solución política a esta cuestión en el marco de la Misión de las Naciones Unidas de Vigilancia, Verificación e Inspección y del Organismo Internacional de Energía Atómica. En este sentido, deseo compartir con el Consejo de Seguridad algunas de mis opiniones.

En primer lugar, el Iraq debe aplicar las resoluciones pertinentes del Consejo de Seguridad de forma estricta, plena y seria. Exhortamos a la parte iraquí a que reconozca plenamente la urgencia e importancia de las inspecciones y proporcione una mayor cooperación de manera más activa. La última visita a Bagdad de los dos inspectores jefes de las Naciones Unidas ha dado algunos resultados positivos. La parte iraquí ha asumido ciertos compromisos. Pedimos al Iraq que cumpla con esas promesas lo antes posible y que proporcione aclaraciones y explicaciones cuanto antes con respecto a las preguntas planteadas por los dos inspectores jefes en los informes que presentaron anteriormente.

En segundo lugar, es necesario que continúe la labor de inspección en el Iraq. En la resolución 1441 (2002) del Consejo de Seguridad se estipula que las inspecciones cuentan con una autorización explícita y exigen requisitos concretos.
Buscar la aplicación de esta resolución sigue siendo una tarea importante para nosotros. En este sentido, el Consejo de Seguridad y los dos órganos de inspección todavía tienen mucho por hacer. A juzgar por lo que se logró en el pasado reciente, la labor de inspección ha avanzado y se han aclarado algunas cuestiones. No obstante, también se han descubierto nuevos elementos en ese proceso. Los dos órganos tienen el deber y justificación para seguir con las inspecciones con el objetivo de hallar la verdad y cumplir con la misión que les ha conferido el Consejo de Seguridad. Por consiguiente, de acuerdo con la opinión de la mayoría de los miembros del Consejo, China considera que el proceso de inspección funciona y que debería seguir dándose a los inspectores el tiempo que necesitan para aplicar la resolución 1441 (2002).

En tercer lugar, el Consejo de Seguridad debe acelerar sus esfuerzos en cuanto a las inspecciones. La cuestión del Iraq afecta la paz y la estabilidad en la región del Golfo y la credibilidad y autoridad del Consejo de Seguridad. El Consejo debe tratar esta compleja situación de manera adecuada y responsable de conformidad con los propósitos y principios establecidos en la Carta, para así dar cumplimiento a su importante tarea de mantener la paz y la seguridad internacionales. Ahora debe darse prioridad absoluta al fortalecimiento de sus directrices y apoyo para la labor de inspección y para facilitar una solución política productiva. La intensificación de las inspecciones tiene como objetivo buscar una solución pacífica de la cuestión del Iraq. China está dispuesta a seguir proporcionando a ambos órganos el personal y la asistencia técnica necesarios para así continuar con nuestros esfuerzos por lograr una solución política de la cuestión del Iraq.

China es una civilización antigua. Nuestros antepasados hace mucho tiempo ya propusieron la idea de que la paz es la mejor opción. Actualmente, la paz y el desarrollo son las aspiraciones comunes de todos los pueblos del mundo. Al estar aquí en el Consejo de Seguridad, no tenemos motivos para no esforzarnos todo lo posible para lograr ese objetivo y estamos obligados a tratar de hacer todo lo posible y a utilizar todos los medios disponibles para evitar la guerra. Sólo si nos decidimos por una solución política, realmente podremos estar a la altura de la confianza y la esperanza que la comunidad internacional deposita en el Consejo de Seguridad. 